\title{
Pengaruh Suhu Pertumbuhan terhadap Laju Penumbuhan Kristal Tunggal Garam Rochelle $\left(\mathrm{KNaC}_{6} \mathrm{H}_{6} \mathrm{O}_{6} \cdot \mathbf{4} \mathrm{H}_{2} \mathrm{O}\right)$
}

\author{
Thoifah* $^{*}$ dan Frida U. Ermawati ${ }^{\dagger}$ \\ Jurusan Fisika, Universitas Negeri Surabaya 60231 Indonesia
}

\begin{abstract}
Intisari
Laju penumbuhan kristal dipengaruhi beberapa hal antara lain sifat zat itu sendiri, suhu (larutan dan lingkungan), dan gangguan mekanik. Salah satu suhu larutan yaitu suhu pertumbuhan (Growth Temperature) dan makalah ini berisi tentang pengaruh suhu pertumbuhan terhadap laju penumbuhan kristal tunggal garam Rochelle. Suhu pertumbuhan yaitu suhu larutan pada saat kristal tunggal tumbuh. Dalam penelitian ini, digunakan variasi suhu pertumbuhan $25^{\circ} \mathrm{C}, 30^{\circ} \mathrm{C}$, dan $35^{\circ} \mathrm{C}$ dan konsentrasi $0,0046 \mathrm{M}$. Metode yang digunakan dalam penelitian ini adalah Slow Cooling. Hasil dari penelitian ini yaitu pada suhu $30^{\circ} \mathrm{C}$ mempunyai laju pertumbuhan yang paling optimum artinya pada suhu tersebut kristal tunggal garam Rochelle dapat tumbuh dengan ukuran yang besar, dan bentuk yang paling sempurna pada waktu yang telah ditentukan (60 jam). Hasil difraksi sinar-X menunjukkan bahwa bahan serbuk dan kristal tunggal garam Rochelle yang ditumbuhkan mempunyai parameter kisi monoklinik, hal ini diketahui setelah nilai d dan 2 dari database dicocokkan dengan data pengukuran dan data perhitungan yang meggunakan rumus parameter kisi monoklinik $(a=11,87 \AA$, $b=14,32 \AA$, dan $\mathrm{c}=6,23, \beta=89,4333^{\circ}$ ).
\end{abstract}

KATA KUNCI: kristal, suhu pertumbuhan, laju pertumbuhan, slow cooling, difraksi sinar-X.

\section{PENDAHULUAN}

Seperti telah dipahami bahwa terdapat tiga faktor yang mempengaruhi pertumbuhan kristal [1] yaitu (i). sifat zat itu sendiri, meliputi tingkat keterlarutan bahan, derajat keasaman, dan tingkat kejenuhan, (ii). suhu, meliputi suhu lingkungan dan suhu larutan yang salah satunya adalah suhu pertumbuhan (Growth Temperature), (iii). gangguan mekanik. Dalam penelitian ini peneliti memfokuskan pada faktor suhu pertumbuhan saja, sebab faktor sifat zat sedang dipelajari oleh anggota tim yang lain, sedangkan faktor yang ketiga diasumsikan bisa dijaga konstan dengan memanfaatkan pengalaman peneliti selama bekerja dengan bahan garam Rochelle.

Garam Rochelle (GR) dipilih sebagai bahan penelitian karena studi literatur [2] menunjukkan bahwa GR relatif aman dipakai dalam penelitian dan kristal tunggal GR dapat ditumbuhkan dengan baik dari larutannya, serta bahan GR banyak tersedia di toko bahan kimia.

\section{DASAR TEORI}

Potassium sodium tartrate $\mathrm{KNa}\left(\mathrm{C}_{4} \mathrm{H}_{4} \mathrm{O}_{6}\right) \cdot 4 \mathrm{H}_{2} \mathrm{O}$ dibuat pertama kali oleh seorang apoteker pada tahun 1675 bernama Pierre Seignette di La Rochelle Prancis, sehing ga garam tersebut dikenal sebagai garam Seignette atau garam Rochelle. Ba-

\footnotetext{
*E-MAIL: ifahamdi@yahoo.com

${ }^{\dagger}$ E-MAIL: Frida_duadyahoo.com
}

han ini tidak berwarna, sedikit larut dalam alkohol, tetapi lebih banyak larut dalam air, kerapatan $1,79 \mathrm{gr} / \mathrm{ml}$, titik lebur $75^{\circ} \mathrm{C}$, mempunyai rasa yang asin dan mempunyai sistem kristal orthorombik dengan harga a b c yaitu a $=11,899 \AA$ A, $\mathrm{b}=14,279$ $\stackrel{\circ}{A}, \mathrm{c}=6,229 \stackrel{\circ}{A}$, dengan sudut $\alpha=\beta=\gamma=90^{\circ}$. Dalam dunia kesehatan, garam Rochelle ini digunakan sebagai obat pencahar, serta digunakan dalam mikrofon karena efek piezoelektrik ketika diberi tegangan.

Seperti telah disebutkan didepan bahwa suhu dalam penumbuhan kristal dapat mempengaruhi laju penumbuhan kristal. Suhu larutan yang tinggi dapat mempercepat pertumbuhan kristal [3].

Beberapa suhu yang berkaitan dengan proses penumbuhan kristal antara lain[4]:

1. Suhu nukleasi (nucleation temperature), yaitu suhu ketika suatu larutan membentuk inti. Proses pengintian (nucleation) akan lebih cepat terjadi pada suhu tinggi bergantung pada jenis bahan. Untuk larutan garam Rochelle suhu nukleasi adalah $(31,0 \pm 0,5){ }^{\circ} \mathrm{C}$.

2. Suhu saturasi (saturation temperature), yaitu suhu ketika larutan tepat akan jenuh. Kristal akan terbentuk ketika larutan tepat jenuh. Ketidakjenuhan mungkin terjadi ketika suhu saturasi meningkat walaupun sedikit, bergantung pada jenis larutan. Untuk larutan garam Rochelle suhu saturasi adalah $(32,0 \pm 0,1){ }^{\circ} \mathrm{C}$.

3. Suhu Pertumbuhan (growth temperature) yaitu suhu pada saat kristal itu tumbuh. Setelah proses nukleasi maka kristal itu akan tumbuh, untuk larutan garam Rochelle suhu pertumbuhan adalah $(30,5 \pm 0,1){ }^{\circ} \mathrm{C}$ 


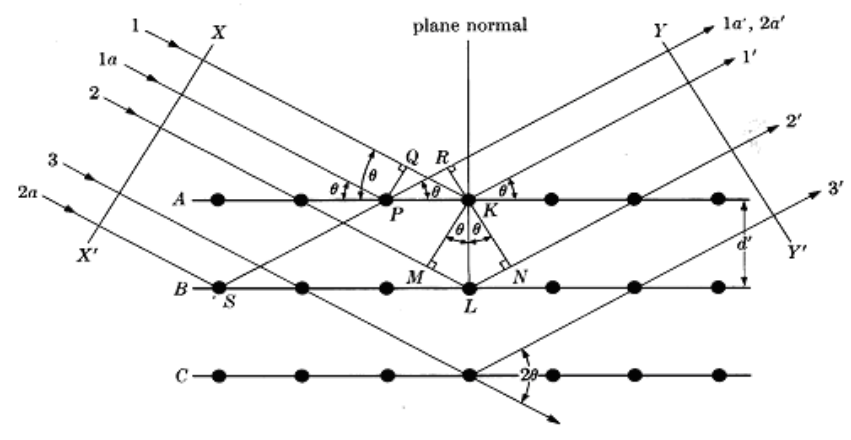

Gambar 1: Sinar-X 1 dan 2 menumbuk atom K, dan L pada bidang kristal A, dan B membentuk sudut (11)

4. Suhu Ketidaklarutan ( dissolution temperature) yaitu suhu ketika bahan terlarut sudah tidak dapat larut dalam larutan lagi, untuk larutan garam Rochelle suhu ketidaklarutan adalah $(36,0 \pm 0,2){ }^{\circ} \mathrm{C}$.

Sinar $\mathrm{X}$ adalah gelombang elektromagnetik yang mempunyai panjang gelombang $0,5-2,5 \stackrel{\circ}{A}[5]$. Proses difraksi sinar-X terjadi ketika berkas monokromatis mengenai bidang kristal, maka oleh bidang kristal A, B, dan $\mathrm{C}$ akan dihamburkan ke segala arah (scattering). Hamburan pada sudut-sudut tertentu dan merupakan gabungan dari gelombang-gelombang yang sefase dan saling menguatkan akan menghasilkan difraksi sinar-X.

Pada Gambar 1, beberapa sinar-X yang menumbuk atomatom atau molekul pada bidang kristal $\mathrm{A}, \mathrm{B}$, dan $\mathrm{C}$ dengan panjang gelombang tertentu $(\lambda)$ akan mempunyai sudut datang $\theta$ terhadap permukaan bidang kristal (disebut sudut Bragg). Panjang gelombang sinar-X $(\lambda)$ harus mempunyai nilai orde yang sama dengan jarak antar atom terdekat (d). Bidang - bidang kristal (A, B, C) disebut bidang Bragg. Jika sinar-1 menumbuk bidang A pada atom $\mathrm{K}$, dan sinar-2 menumbuk atom $\mathrm{L}$ pada bidang $\mathrm{B}$ maka besar beda lintasan antara kedua sinar-X tersebut adalah

$$
M L+L N=d \sin \theta+d \sin \theta=2 d \sin \theta
$$

Difraksi sinar-X terjadi apabila sinar- 1 dan sinar- 2 berinterferensi dan saling menguatkan. Jika sinar-2 menempuh jarak lebih jauh dari sinar-1 sebesar $2 \mathrm{~d} \sin \theta$, maka perbedaan panjang lintasan antara sinar- 1 dan sinar-2 harus merupakan kelipatan bulat dari panjang gelombang berkas sinar-X yang menumbuk bidang atom, dan dikenal dengan hukum Bragg.

$$
2 d \sin \theta=n \lambda
$$

dengan $\mathrm{n}$ menyatakan bilangan orde difraksi merupakan bilangan bulat.

\section{METODOLOGI PENELITIAN}

Proses penumbuhan kristal tunggal garam Rochelle dilakukan di laboratorium Fisika Material UNESA selama lima

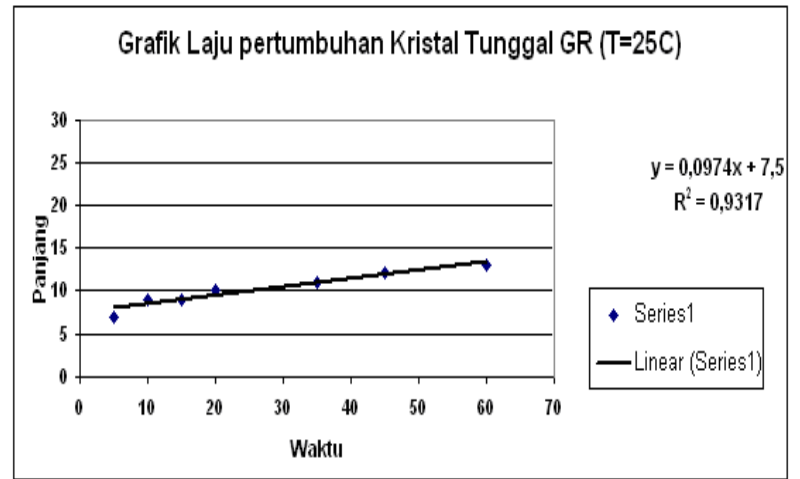

Gambar 2: Grafik laju pertumbuhan kristal garam Rochelle pada suhu pertumbuhan $25^{\circ} \mathrm{C}$

minggu mulai bulan Desember 2006 sampai bulan Januari 2007. Suhu pertumbuhan dijaga konstan untuk masingmasing sampel. Karakteristik bahan menggunakan uji difraksi sinar-X yang dilakukan di laboratorium Uji Polimer LIPI Bandung.

Variabel bebas pada penelitian ini adalah suhu pertumbuhan yaitu suhu pada saat kristal itu bertambah ukurannya. Suhu pertumbuhan yang digunakan pada penelitian ini adalah $25^{\circ} \mathrm{C}, 30^{\circ} \mathrm{C}, 35^{\circ} \mathrm{C}$. Berdasarkan referensi, suhu pertumbuhan kristal garam Rochelle adalah $30,5^{\circ} \mathrm{C}$ dan rentang digunakan berdasarkan hasil kegiatan pra eksperimen. Alat ukur yang digunakan yaitu termometer alkohol dan heater. Variabel terikat pada penelitian ini adalah ukuran kristal, waktu penumbuhan dan laju penumbuhan. Alat ukur panjang kristal yang digunakan yaitu penggaris dengan skala $1 \mathrm{~mm}$. Variabel kontrol pada penelitian ini yaitu bahan serbuk garam Rochelle, molaritas, heater, mikroskop Stereo (merk Cenco 62090-2) dengan perbesaran $30 \mathrm{X}$, web camera (merk Logitech), dan mesin difraksi (merk Rigaku) yang berada di Lab. Uji polimer LIPI Bandung, digunakan untuk menguji keteraturan internal bahan garam Rochelle.

Tahapan metode penelitian yang dilakukan terlihat pada diagram alir Gambar 3.

\section{HASIL DAN DISKUSI}

Grafik pada Gambar 2 menunjukkan bahwa pada suhu pertumbuhan $25^{\circ} \mathrm{C}$, laju pertumbuhannya $0,0974 \mathrm{~mm} / \mathrm{jam}$, sedangkan pada saat suhu pertumbuhannya $30^{\circ} \mathrm{C}$ laju pertumbuhannya sebesar $0,2494 \mathrm{~mm} / \mathrm{jam}$. Pada saat suhu pertumbuhannya $35^{\circ} \mathrm{C}$, kristal lambat sekali pertumbuhannya (pada saat jam ke empat baru tumbuh kristal), tetapi setelah kristal tumbuh, hasilnya tidak dapat diukur karena antar kristal bertumpukan (Twin).

Dari grafik di atas menunjukkan bahwa laju paling optimum pada saat suhu pertumbuhannya $30^{\circ} \mathrm{C}$. Hal ini dikarenakan tumbukan antar partikel seimbang (equilibrium), artinya dalam tumbukan antar partikel, penyatuan dan pemisahan ikatan partikel berlangsung seimbang [6]. Kristal pada suhu $30^{\circ} \mathrm{C}$ mempunyai ukuran yang paling besar dan bentuk 


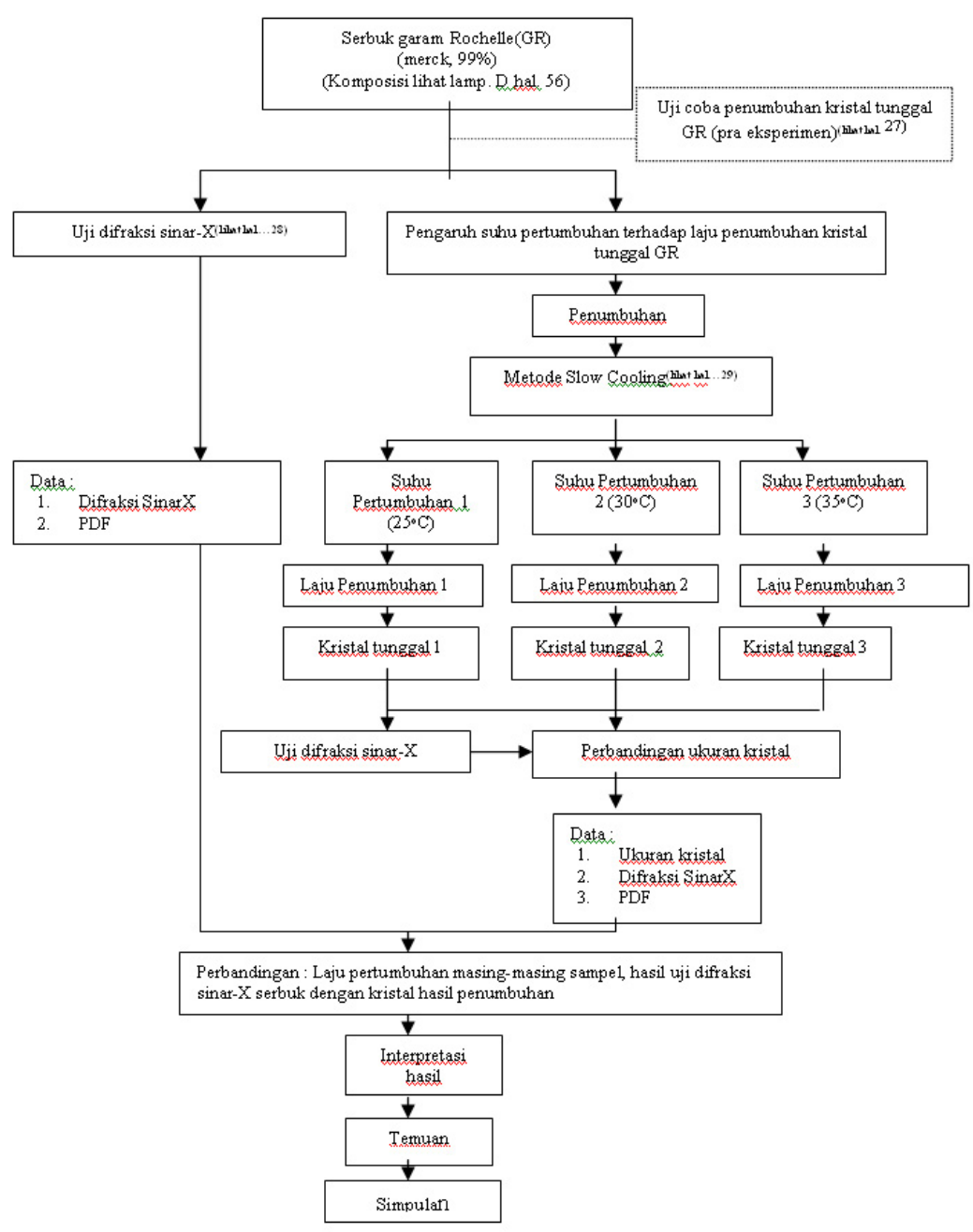

Gambar 3: Diagram alir metode penelitian

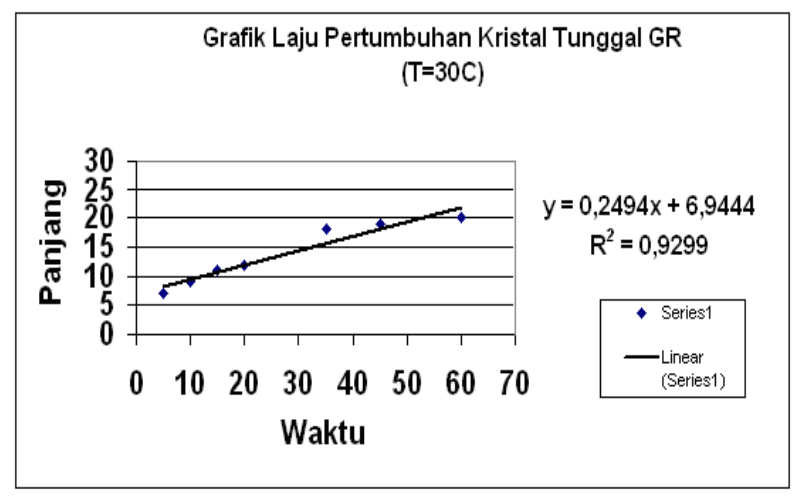

Gambar 4: Grafik laju pertumbuhan kristal garam Rochelle pada suhu pertumbuhan $30^{\circ} \mathrm{C}$

yang paling sempurna. Pada suhu pertumbuhan $25^{\circ} \mathrm{C}$, laju pertumbuhannya lebih kecil dari suhu pertumbuhan $30^{\circ} \mathrm{C}$, hal ini dikarenakan pada suhu pertumbuhan dibawah suhu optimum, tumbukan antar partikel berlangsung tidak seimbang.

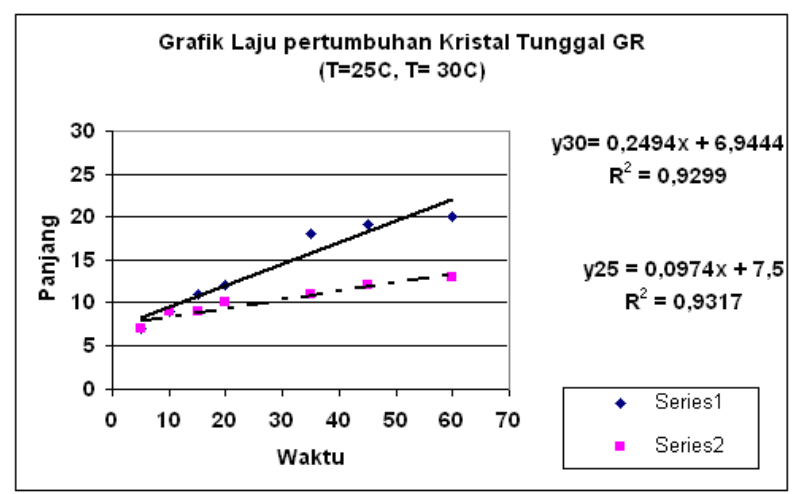

Gambar 5: Grafik laju pertumbuhan kristal garam Rochelle pada suhu pertumbuhan $25^{\circ} \mathrm{C}$ dan $30^{\circ} \mathrm{C}$

Proses penyatuan partikel lebih besar dari proses pelepasan partikel sehingga menghambat pertumbuhan kristal, dan kristal menjadi kotor. Sedangkan pada suhu pertumbuhan di atas suhu optimum $\left(35^{\circ} \mathrm{C}\right)$, proses pelepasan ikatan antar par- 


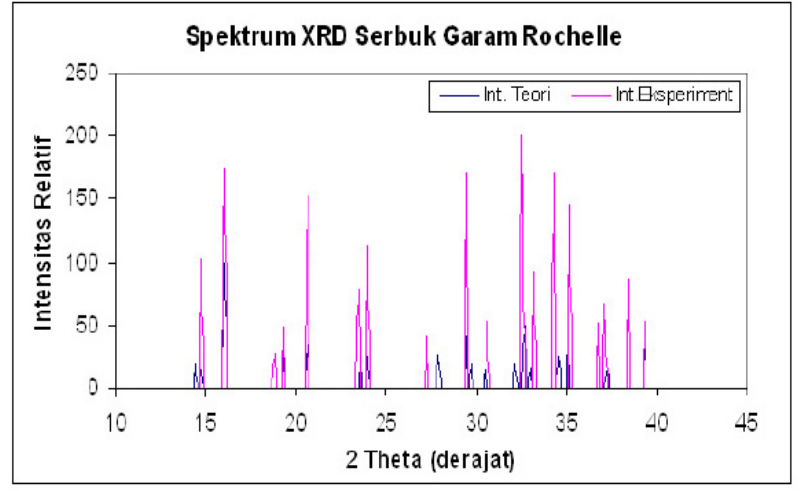

Gambar 6: Hasil difraksi sinar-X Garam Rochelle berupa Serbuk

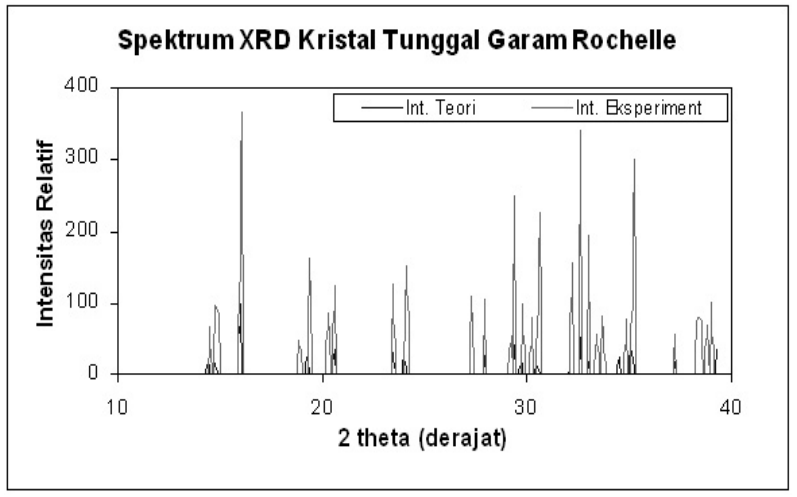

Gambar 7: Hasil Difraksi sinar-X garam Rochelle berupa Kristal.

tikel lebih besar dari proses penyatuan antar ikatan partikel, sehingga proses kesetimbangan tidak tercapai. Kristal yang terbentuk pada kondisi ini berpasir dan bertumbukan (Twin Crystal) sehingga kristal tidak dapat diukur selama penum- buhan. Pada $\mathrm{T}=35^{\circ} \mathrm{C}$ mulai muncul biji kristal pada jam keempat dengan keadaan belum dapat diukur. Pada jam selanjutnya bertumpuk-tumpuk (twin).

Hasil uji difraksi sinar-X dari serbuk garam Rochelle dan kristal tunggal garam Rochelle seperti Gambar 6 dan 7.

Berdasarkan literatur [7] menyebutkan bahwa kristal yang ditumbuhkan pada suhu dibawah $255 \mathrm{~K}\left(-18^{\circ} \mathrm{C}\right)$ dan pada suhu diatas $297 \mathrm{~K}\left(+24^{\circ} \mathrm{C}\right)$ mempunyai parameter kisi monoklinik. Hal ini dikarenakan kristal yang ditumbuhkan pada suhu tersebut mengalami inversi symetri breaking yaitu perubahan parameter kisi kristal. Pada penumbuhan kristal garam Rochelle pada suhu ruang $\left(32^{\circ} \mathrm{C}\right)$ terjadi inversi symetri breaking dari pameter kisi orthorombik menjadi monoklinik. Dari hasil difraksi sinar-X dapat diketahui nilai d dan $2 \theta$ pada serbuk dan kristal tunggal garam Rochelle, kemudian dipilih nilai d dan $2 \theta$ yang sesuai dengan database. Di dapatkan hasil bahwa 18 nilai d dan 18 nilai $2 \theta$ pada database garam Rochelle sesuai dengan nilai d dan $2 \theta$ yang telah dipilih dari data pengukuran serbuk dan kristal tunggal garam Rochelle.

Dari hasil analisis database, data perhitungan, dan data pengukuran untuk serbuk dan kristal tunggal garam Rochelle kemudian dicocokkan nilai d dan $2 \theta$ dengan indeks Miller hkl sehingga didapatkan data indeks Miller untuk masing-masing nilai d dan $2 \theta$.

\section{SIMPULAN}

Bidang hkl (struktur kristal) uji difraksi sinar-X pada kristal garam Rochelle sesuai dengan bidang hkl serbuk garam Rochelle dan laju pertumbuhan kristal garam Rochelle paling optimum pada saat suhu pertumbuhannya $30^{\circ} \mathrm{C}$. Parameter kisi garam Rochelle pada suhu diatas $297 \mathrm{~K}\left(+24^{\circ} \mathrm{C}\right)$ adalah monoklinik.
[1] http://www.Xray.ncsu.edu.Boyle.P.D., Growing Crystal That Will Make Your Crystallographer Happy, (tanggal akses : 19 juni 2006)

[2] http://www.answer.com., Potasium Sodium Tartrate. (tanggal akses 5 oktober 2005)

[3] Syukri, Kimia Dasar, ITS, (1999)

[4] Mitrovic, Improvement of Initial Condition of the Crystal Growth by Dissolution on Refaceting, Departement of Physics, Yugoslavia (2000)

[5] Cullity, B. D., Element of X-rays Difraction), Second Edition. Addison-wesley (1978)

[6] Sukardjo, Prof. Dr., Kimia Anorganik, Rineka Cipta, Jakarta (1990).

[7] www.Rochellesalt on Webmineral.com/ chemical institute of
Canada Crystal Growing Competition.(tanggal akses 5 oktober 2005 )

[8] Rajendran, V; Mariakni, A., Material Science, Tata McGraw. Hill, New Delhi (2004)

[9] Callister, William D., Material Science and Engineering An Introduction, John Willey\&Sons, New York (2005)

[10] Kittel,C., Introduction to Solid State Physics, $6^{\text {th }}$-ed, John Wiilley \& Sons, New York (1990)

[11] Katalog, merck Potassium Sodium Tartrate, PT. Dianum. Jl. Biliton no. 11 Surabaya.

[12] Data hasil uji Difraksi sinar-X. Pengujian sample dilakukan tanggal 17 januari 2007 di lab. Ui polimer LIPI bandung, (JCPDS dengan nomor PD 11085) 
TABEL I: Perbandingan nilai d dan $2 \theta$ hasil pengukuran difraksi sinar-X serbuk dan kristal tunggal GR

\begin{tabular}{|c|c|c|c|c|c|c|c|}
\hline \multirow[t]{2}{*}{$\overline{\overline{N o}}$} & \multicolumn{3}{|c|}{$\bar{d}$} & \multicolumn{3}{|c|}{$2 \theta$} & \multirow[t]{2}{*}{ hkl } \\
\hline & Serbuk GR & Kristal tunggal GR & $\Delta \mathrm{d}$ & Serbuk GR & Kristal tunggal GR & $\Delta 2 \theta$ & \\
\hline 1 & 5.514 & 5.521 & -0.007 & 16.060 & 16.040 & 0.02 & 101 \\
\hline 2 & 2.749 & 2.774 & -0.025 & 32.540 & 32.240 & 0.3 & 420 \\
\hline 3 & 3.034 & 3.030 & 0.004 & 29.420 & 29.460 & -0.04 & 321 \\
\hline 4 & 2.546 & 2.545 & 0.001 & 35.220 & 35.240 & -0.02 & 132 \\
\hline 5 & 4.304 & 4.300 & 0.004 & 20.620 & 20.640 & -0.02 & 201 \\
\hline 6 & 2.286 & 2.285 & 0.001 & 39.380 & 39.400 & -0.02 & 440 \\
\hline 7 & 4.591 & 4.567 & 0.024 & 19.320 & 19.420 & -0.1 & 220 \\
\hline 8 & 3.792 & 3.770 & 0.022 & 23.440 & 23.580 & -0.14 & 031 \\
\hline 9 & 3.696 & 3.684 & 0.012 & 24.060 & 24.140 & -0.081 & 221 \\
\hline 10 & 3.195 & 3.191 & 0.004 & 27.900 & 27.940 & -0.04 & 231 \\
\hline 11 & 2.609 & 2.608 & 0.001 & 34.340 & 34.360 & -0.02 & 051 \\
\hline 12 & & 6.087 & & & 14.540 & & 120 \\
\hline 13 & & 2.996 & & & 29.800 & & 141 \\
\hline 14 & & 2.774 & & & 32.240 & & 122 \\
\hline 15 & 2.690 & 2.711 & -0.021 & 33.280 & 33.020 & 0.26 & 212 \\
\hline 16 & 2.418 & 2.415 & 0.003 & 37.160 & 37.200 & -0.04 & 321 \\
\hline 17 & 5.973 & 5.949 & 0.024 & 14.820 & 14.880 & -0.06 & 200 \\
\hline 18 & 2.912 & 2.912 & 0 & 30.680 & 30.680 & 0 & 410 \\
\hline
\end{tabular}

